\title{
BREVE REFLEXÃO SOBRE A POSSIBILIDADE DE EXTENSÃO DA PLATAFORMA CONTINENTAL ALÉM DAS 200 MILHAS MARÍTIMAS*
}

\author{
Marisa Cactano Ferrão**
}

\section{IN'TRODUÇÃO}

Apesar de ser um conceito relativamente recente na linguagem jurídica (embora desde há muito seja objecto de estudo por parte de outras áreas do saber), a plataforma continental e o seu regime têm sido eleitos como tema de inúmeros trabalhos por parte dos juristas.

Pela riqueza dos recursos que normalmente the estão associados, tornou-se alvo do interesse dos Estados costeiros, facto que determinou não apenas o seu «nascimento» em termos jurídicos, como também o seu rápido florescimento.

O nosso propósito neste estudo consiste em examinar a noção de plataforma continental, principalmente a possibilidade da sua extensão além das 200 milhas, assim como o papel desempenhado pela Comissão de Limites da Plataforma Continental (daqui em diante designada abreviadamente por Comissão de Limites), e demonstrar a importância da análise efectuada por um jurista numa matéria, como esta, em que se imbricam conceitos pertencentes a outras ciências, como a cartografia, a oceanografia, a geodesia, a geografia e a geologia.

\footnotetext{
"O presente estudo corresponde, com pequeníssimas alterações, à comunicação proferida pela autora nas Jornadas do Mar 2006, "Os Oceanos: Uma Plataforma para o Desenvolvimento", realizadas na Escola Naval, em Almada, de 13 a 17 de Novembro de 2006 , e à qual foi atribuido o $1^{\circ}$ prémio em ex-aequo no $2^{\circ}$ Escalão (Estudos Pós- Graduados) da área das Relações Internacionais, do Direito e da Estratégia.

"Docente na Escola Superior de Tecnologia e Gestão, do Instituto Politécnico de Leiria.
} 


\section{O CONCEITO DE PLATAFORMA CONTINENTAL}

Em termos físicos a plataforma continental consiste na planície submersa adjacente ao território dos Estados costeiros.

Juridicamente o conceito de plataforma continental surgiu com a Proclamação Truman dos EUA, de 28 de Setembro de $1945^{1}$, na qual o Governo desse país declarava possuir jurisdição e controlo sobre os recursos naturais existentes no solo e subsolo da sua plataforma ${ }^{2}$. No texto da referida Proclamação não era estabelecida a extensão da plata-

1 No entanto, Jean-François PULVENIS, "The Continental Shelf Definition and Rules Applicable to Resources", in DUPUY, René-Jean / VIGNES, Daniel (edits), A Handbook on the New Law of the Sea, volume I, Martinus Nijhoff Publishers, Dordrecht - Boston - Lancaster, 1991 , pág. 322 e 323, refere que já anteriormente a essa altura existia um interesse juridico pela plataforma continental. No mesmo sentido, vide Jaime VALLE, "A Plataforma Continental -- Alguns Aspectos do seu Actual Regime Juridico", in Revista Juridica, n" 25, Abril 2002, pág. 38. Sobre o interesse dos geógrafos pela mesma, vide Michael F. WALLACE, "Introduction", in Research Centre for International Law - Universily of Cambridge, Intennational Boundary Cases: The Continental Shelf, Volume One, Grotius Publications Limited, Cambridge, 1992, pág. 2.

2 De acordo com Nuno Sérgio MARQUES ANTUNES, A Delimitação de Espaços Maritimos, (Policopiado), Biblioteca da Faculdade de Direito da Universidade de Lisboa, Lisboa, 1996, pág. 17, a Proclamação Truman deu "um impulso decisivo a um novo movimento em torno da apropriaçáo dos espasos maritimos e do cumento da sua extensão". A referida Proclamação foi considerada pelo Tribunal Internacional de Justiça nos Casos da Plataforma Continental do Mar do Norte, International Court of Justice Reports 1969 , pág. 32 e 33, par. 47, como o "starting point of the posilive law on the subject". Duarte Manuel LYNCF DE FARIA, "A Jurisdição c a Delimitação dos Espaços Marítimos em Portugal - Do Rio Minho às llhas Selvagens, na Golada do Guadiana e no Mar de Timor", in Revista Juridica, 17 "25, Abril 2002, pág. 156, considera a referida Proclamação "a pedra de toque nesta matérica". De acordo com António SOARES, "Plataforma Continental ... seus limites à luz da Convenção de Montego Bay", in Revista do Ministério Público, n" 38, ano 10", Abril-Junho 1989, pág. 16, na origem desta Proclamação estiveram interesses de segurança nacional e interesses económicos. No mesmo sentido, vide VALLE, "A Plataforma Continental...", cil., pág. 39. Para mais desenvolvimentos sobre a referida Proclamação, vide Laurent LUCCHIINI e Michel VOELCKEL, Droit de la Mer; Tome 1.- La mer et son droit - Les esperces maritimes, Éditions A. Pedone, Paris, 1990, pág. 235 e 236; e Fernando LOUREIRO BASTOS, A Intemacionalização dos Recursos Naturais Marinhos - Contributo para a compreensäo do Regime Juridico-Internacional do Aproveitamento Conjunto de Petróleo e de Gás Natural nas Plataformas Continentais, do Potencial Aproveitamento de Recursos Minerais na Área, da Pesca no Alto Mar e o.s Efeitos da Regulamentação Convencional Respectiva em Relaçäo a Tereiros Estados, AAFDL, Lisboa, 2005, pág. 286 e 287. 
forma, mas apenas num Memorandum que consagrava como limite a isóbata dos 200 metros $^{3}$. Assim, nessa declaração a noção de plataforma coincidia com o seu sentido em termos físicos, considerando-a como o prolongamento natural do território terrestre.

Na sequência desse documento muitas declarações unilaterais de outros Estados costeiros se the seguiram ${ }^{4}$. No entanto, essas declarações nem sempre seguiram de perto o conteúdo da referida Proclamação, como o demonstra, inter alia, a Declaração de Santiago do Chile de 1952 efectuada pelo Peru, pelo Chile e pelo Equador, em que estes reivindicaram os seus poderes exclusivos sobre o mar adjacente (e não apenas em relação ao território terrestre submerso) às suas costas numa extensão de 200 milhas maritimas (o que causou protestos de alguns países) ${ }^{5}$. De salientar que estes Estados não dispõem de uma plataforma continental em termos geológicos, e que o objectivo da declaração era apenas o de estabelecer um acesso exclusivo aos recursos pesqueiros daquela zonat.

Em termos de direito positivo, a previsão da plataforma continental ocorreu pela primeira vez com a Convenção de Genebra de $1958^{7}$. Contudo, o critério usado para estabelecer os seus limites era extremamente flexível ${ }^{8}$. Efectivamente, embora a primeira parte da alínea a)

3 Cfr. WALLACE, "Introduction", cit., pág. 2; e LUCCHINI e VOFLCKEL, Droil de la Mer.., cit., pág. 243. De salientar que a referida proclamação apenas dizia respeito aos minerais. Cfr. M. W. MOUTON, "The Continental Shelf", in $R D C$, volume 85, 1954 I... pág. 410; e Malcolm N. SHAW, International Law, 4" Edição, Cambridge University Press, Cambridge, 1997, pág. 435.

4 Sobre a multiplicidade dos actos unilaterais, vide LUCCHINI e VOELCKEL, Droit de la Mer..., cit., pág. 236, cuja lista não é, contudo, exaustiva.

5 Cfr. SOARES, "Plataforma Continental...", cit., pág. 20. Sobre esta declaração, vide, inter alia, Joaquim da SILVA CUNHA e Maria da Assunção do VALE PEREIRA, Mamual de Direilo Iniernacional Público, Almedina, Coimbra, 2004, pág. 612.

"Cfr. Nuno MARQUES ANTUNES, Towards the Conceptuatisation of Maritime Delimilation -- legal and Technical Aspects of Political Process, Martinus Nijhoff Publishers, Leiden - Boston, 2003, pág. 14; e PULVENIS, "The Continental Shelf Defini-lion...", cil., pág. 326.

7 A Convençăo de Genebra sobre a Plataforma Continental, assinada em 29 de Abril de 1958, foi publicada em língua francesa e portuguesa no Diário do Governo de 3 de Agosto de 1962 e iniciou a sua vigência internacionalmente (e também em relação a Portugal) em 10 de Junho de 1964.

${ }^{8}$ Daí que o referido artigo tenha sido objecto de acesas críticas e, por isso, a definição da plataforma continental tenha sido completamente alterada com a Convenção de Montego Bay. Neste sentido, vide Edward D. BROWN, "Maritime Zones: A Survey of 
do artigo $1^{\circ}$ consagrasse um critério mais preciso ao estabelecer como limite a profundidade dos 200 metros, a segunda parte estabelecia como alternativa o critério da explorabilidade associada à profundidade, que é bastante elástico". Assim, o critério da explorabilidade tornava inútil o referido limite da profundidade ${ }^{10}$, uma vez que aquele fazia depender os referidos limites do estado da técnica, podendo conduzir a que, no futuro, os Estados adquirissem direitos de soberania sobre todo o fundo do oceano, desde que fosse inventada tecnologia que permitisse a sua exploração". Foi exactamente a utilização deste critério que permitiu que o próprio conceito de plataforma continental se fosse tornando mais abrangente. Desta forma, nesta Convenção o conceito jurídico de plataforma não correspondia ao seu conceito em termos físicos, nem estava previsto como o prolongamento natural do território dos Estados.

Claims", in CHURCHILL, Robin / SIMMONDS, Kenneth R. / WELCH, Jane (edits.), New Directions in the Law of the Sea-Collected Papers, Volume II, Oceana Publications Inc., New York, 1973, pág. 186. Quanto aos perigos do critério da explorabilidade, vide igualmente Robin R. CHURCHILL e Alan V. LOWE, The Law of the Sea, $2^{\text {: }}$ Edição, Manchester University Press, Manchester, 1988, pág. 125. Embora se tenha tentado evitar uma utilização abusiva do referido critério ao consagrar a exigência da adjacência às costas, prevista no artigo $1^{\circ}$ da referida Convenção. Neste sentido, vide PULVENIS, "The Continental Shelf Definition...", cit., pág. 347 e 348, que, todavia, considera que esse objectivo não foi alcançado; e VALLE, "A Plataforma Continental...", cit., pág. 40.

"O artigo em causa tem a seguinte redacção: "Para os fins dos presentes artigos a expressão "plataforma continental» é utilizada para designar: a) o leito do mar e o subsolo das regiöes submarinas adjacentes às costas mas situadas fora do mar territorial até uma profundidade de $200 \mathrm{~m}$ ou, para além deste limite, até ao ponto onde a profundidade das águas superjacentes permita a explofação dos recursos naturais das diras regiöes; b) o leito do mar e o subsolo das regiões submarinas análogas que são adjacentes às costas das ilhas".

10 Neste sentido, vide PULVENIS, "The Continental Shelf Definition...", cit., pág. 347. Trata-se da chamada «open ended clause» (Cfr. SOARES, "Plataforma Continental...", cit,, pág. 22) ou «sweeping clause» (cfr. BERNHARDT, "Custom and treaty in the law of the sea", in RDC, volume 205, 1987 .. V, pág. 293).

1 Neste sentido, vide MARQUES ANTUNES, A Delimitação de Espaços..., cit., pág. 78 , nota de rodapé 225 . No âmbito da sessão de trabalho da Comissão de Direito Intcrnacional em 1950, foi salientado esse perigo do critério da explorabilidade, o que, todavia, não impediu que o mesmo tivesse sido adoptado no ano seguinte no projecto da referida Comissão e, mais tarde, na Convenção de Genebra, embora com algumas alterações. Quanto à possibilidade de exploração para além da isóbata dos 200 metros, vide igualmente PULVENIS, "The Continental Shelf Definition...", cit., pág. 329. 
Foi apenas com a Convenção de Montego Bay ${ }^{2}{ }^{13}$ que os limites exteriores da plataforma continental foram consagrados de uma forma precisa, o que constituiu uma importante inovação introduzida pela mesma ${ }^{14}$. Com efeito, o $n^{\circ} 1$ do artigo $76^{\circ}$ da referida Convenção estabelece que "A plataforma continental de um Estado costeiro compreende o leito e o subsolo das áreas submarinas que se estendem além do seu mar territorial, em toda a extensão do prolongamento natural do seu território terrestre, até ao bordo exterior da margem continental ou até uma distância de 200 milhas maritimas"'s. Desta forma, o conceito de

12. A Convenção das Nações Unidas sobre o Direito do Mar consta da acta final da 111 Conferência das Nações Unidas sobre o Direilo do Mar (1973-1982), assinada em 10 de Dezembro de 1982, em Montego Bay, na Jamaica (e, por isso, também conhecida como Convenção de Montego Bay) c entrou em vigor na ordem internacional em 16 de Novembro de 1994. No entanto, em relação a Portugal a referida Convenção apenas iniciou a sua vigência em 3 de Dezembro de 1997. O texto da mesma em língua poruuguesa foi publicado no Diário da República $n^{\circ} 238$, I Série $\mathrm{A}, 1^{\circ}$ suplemento, de 14 de Outubro de 1997. O texto em lingua inglesa está disponivel no site da ONU, mais concretamente em http://www.un.org/Depts/os/convention_agreements/texts/unclos/ unclos_e.pdf (consultado em 05/05/2006).

${ }^{13}$ Todos os artigos referidos daqui cm diante sem indicação de proveniência pertencem à Convenção de Montego Bay. De acordo com Nuno MARQUES ANTUNES e Fernando M. PIMENTEL, " $\Lambda$ Extensão da Plataforma Continental para além das 200 Milhas", in MARQUTS ANTUNES, Nuno (edit), Estudos em Direito Internacional Público, Almedina, Coimbra, 2004, pág. 321, a Convenção de Montego Bay constitui um "marco histórico". Com efeito, o seu contributo no âmbito do Direito do Mar é indiscutível. No que diz respeito à plataforma continental as negociações foram bastante demoradas e difíceis, devido às diferentes facçôes existentes, o que faz com que a grande maioria do seu regime constitua uma solução de compromisso e o que explica também o carácter bastante complexo de algumas disposições da Convenção. Neste sentido, vide PULVENIS, "The Continental Shelf Definition...", cit., pág. 331.

${ }_{14}$ Todavia, o carácter inovador da Convenção de Montego Bay em relação à Convenção de Genebra na parte relativa à plataforma continental não foi muito além deste aspecto, uma vez, que a grande maioria dos preccitos da primeira são muito semelhantes aos da segunda. Neste sentido, vide LOUREIRO BASTOS, A Internacionalizaçäo dos Recursos Nalurais..., cit., pág. 300, quando se refere a um "aproveilamento quase integrat do articulado da Convenção de Genebra sobre a Plataforma Continental".

is Desta forma, o limite interior da plataforma continental coincide com o limite extefior do mar territorial, tal como já acontecia na Convenção de Genebra. Neste sentido, vide SOARIS, "Plataforma Continental...", cit., pág. 28; Jorge Bacelar GOUVEiA, Mamual de Direito Internacional Público, 2" Edição, Actualizada e Ampliada, Almedina, Coimbra, 2004, pág. 592; c Armando M. MARQUES GUEDES, Direilo do Mor, 2" Edição, Coimbra Editora, Coimbra, 1998, pág. 189. 
plataforma continental (continental shelf) alargou-se, não se confinando esta apenas à planície adjacente ao território dos Estados, e indo até ao bordo exterior da margem continental ${ }^{16}$ (conduzindo, assim, a que o seu significado geológico corresponda apenas em parte ao seu conceito jurídico ${ }^{17}$ ). Efectivamente, a margem continental (continental margin) abrange não apenas a referida planície, mas também o talude continental (continental slope), e a elevação continental (continental rise), mas já não os grandes fundos oceânicos (deep ocean floor), tal como dispõe o $\mathrm{n}^{\circ} 3$ do artigo $76^{\circ}{ }^{18}$. Embora se continue a utilizar a mesma expressão - «plataforma continental» - há autores que criticam esse facto em virtude de o mesmo poder conduzir a confusões ${ }^{1 \%}$.

Assim, actualmente, a plataforma continental coincide com a mar-

16. Neste sentido, Donat PHARAND, "The Law of the Sea:An Overview", in PHARAND, Donat / LEANZA, Umberto (edits), The Continental Shelf and the Exclusive Economic Zone - Delimitation and Legal Regime / Le plateau continental et la zone économique exc/usive, Martinus Nijhoff Publishers, Dordrecht - Boston - London, 1993, afima, na pág. 9, que "the geological margin has become the legal continental shelf under the new convention"; e MARQULS ANTUNES e PIMENTEL, "A Extensão da Plataforma Continental...", cil., pág. 326, falam a este respeito em "plataforma continental jurtidica" ou "plataforma continental legal".

17 Neste sentido, vide MARQUES ANTUNES, A Delimitação de Esperços..., cit., pág. 78 e 79 .

18 Contudo, em The Law of The Sea-Definition of the Continental Shelf. An Examination of the Relevant Provisions of the United Nations Convention on the Law of the Sea, Division for Ocean Affairs and the Law of the Sea, Office of Legal Alfairs, United Nations, New York, 1993, pág. 11, chama-se a atenção para o facto de, na prática, raramente a margem continental ter uma constituição assim tão simples.

19 Neste sentido, Ron MACNAB e P. K. MUKHERJEE, "The 1982 Convention on the Law of the Sea and the Outer Limit of the Continental Shelf: Some Practical Considerations for Wide-Margin States", in PHARAND, Donat / LEANZA, Umberto (edits), The Continental Shelf and the Exclusive Economic Zone-Delimitation and Legal Regime / Le platean continenlal el la zone economique exclusive, Martinus Nijhoff Publishers, Dordrccht - Boston -.. London, 1993, pág. 25, afirmam en relação a essa expressão que "its potential for creating confusion, this is an unfortunate choice of nomenclature". No mesmo sentido, vide SO $\mathrm{RES}$, "Plataforma Continental...", eit., pág. 25, que afirma que "Melhor feria sido que a Convenção passasse a designar esta figura pelo nome de margem continental e não de plataforna". De acordo com Edward D. BROWN, Sea-Bed Energy and Minerals: The International Legal Regime, Volume 1, The Continental Shelf, Martinus Nijhoff Publishers, Dordrecht - Boston -- London, 1992, pag. 23, "In article 76 of the UN Convention, this abuse of the original scientific term is extended ad absurtum". 
gem continental ${ }^{20}$, o que consubstancia um alargamento substancial dos territórios submarinos sujeitos à soberania dos Estados, uma vez que a plataforma continental entendida apenas como a planície corresponde a $7 \%$ do espaço dos oceanos, enquanto que a margem continental corresponde a $21 \%{ }^{21}$. No que diz respeito à sua extensão, a plataforma continental em termos físicos pode alcançar as 600 milhas, enquanto a margem continental pode ir além das $800^{22}$. No entanto, permanece o princípio do prolongamento natural ${ }^{23}$ (expressão contida no próprio texto do artigo $76^{\circ}$ ) do território terrestre dos Estados, tal como foi defendido na Proclamação Truman e pelo Tribunal Internacional de Justiça nos Casos da Plataforma Continental do Mar do Norte ${ }^{24}$. Assim, pelo menos em

${ }^{2}$ Neste sentido, vide LOUREIRO BASTOS, A Internacionalização dos Recursos Naturais..., cit., pág. 285, quando refere que "actualmente, a plataforma continental em termos juridicos corresponde, em termos mais correctos, à margem continental em termos fisicos". Assim, embora o artigo $76^{\circ}$ utilize um conceito juridico de plataforma continental, utiliza o termo margem continental no seu sentido geomorfológico. Neste sentido, vide The Law of The Sea-Definirion..., cit., pág. 10.

2 Neste sentido, vide LOUREIRO BASTOS, A Intenacionalização dos Recursos Naturais..., cit., pág. 285.

22 Neste sentido, vide Jorgen LILJL-JLNSEN e Milan THAMSBORG, "The role of Natural Prolongation in Relation to Shelf Delimitation beyond 200 Nautical Miles", in Nordic Joumal of International Law, volume 64, 17² 4, pág. 623 e 624.

23 Embora o conceito de margem continental agora utilizado desvirtue o princípio, na opinião de LOUREIRO BASTOS, A Internacionalizaçăo dos Recursos Naturais..., cit., pág. 305. VALLE, "A Plataforma Continental...", cit., pág. 41, considera que se trata de uma recuperação desse princípio. Sobre o sentido da expressão «prolongamento natural», vide PULVENIS, "The Continental Shelf Definition...", cit., pág. 338 a 344.

24 Cfr. Casos da Plataforma Continental do Mar do Norte, International Court of Justice Reports 1969 , pág. 36, par. 57, pág. 31, par. 43, entre outras. Embora mais tarde o mesmo Tribunal se tenha vindo a afastar um pouco desse princípio, nomeadamente no Caso da Delimitação entre a Tunisia e a Líbia, International Court of Justice Reports 1982, pág. 46, par. 43; e no Caso da Delimitação da Plataforma Continental entre a Libia e Malta, International Court of Justice Reports 1985, pág 35 e 36, par. 39, 40 e 41. Neste sentido, Umberto LEANZA, "La délimitation du plateau continental el de la zone économique exclusive : une introduction", in PHARAND, Donal / LEANZA, Umberto (edits), The Continental Shelf and the Exclusive Economic Zone ... Delimitation and Legal Regime / Le plateau continental et la zone économique exclusive, Martinus Nijhoff Publishers, Dordrecht - Boston - London, 1993, pág. 49, afirma que "le critère du prolongement naturel dans les délimitations a été définitivement substitué par celui de la distance". No entanto, LILJE-JENSEN e THAMSBORG, "The role of Natural Prolongation...", cit., pág. 625, entendem que "it is beyond doubt that the Court maintains the view that natural prolongation (...) still has a role to play in respect of title to shelf 
parte, mais concretamente no que diz respeito à plataforma além das 200 milhas $^{26}$, o referido princípio mantém-se ${ }^{27}$.

De forma muito breve, podemos assim afirmar que os limites previstos em alternativa no artigo $76^{\circ}$ da Convenção de Montego Bay são: até às 200 milhas marítimas a contar das linhas de base a partir das quais se mede a largura do mar territorial, independentemente das características físicas da plataforma ${ }^{28} \mathrm{e} \mathrm{sem} \mathrm{necessidade} \mathrm{de} \mathrm{qualquer} \mathrm{reivin-}$ dicação por parte do Estado; ou para além das 200 milhas, até ao bordo exterior da margem continenta ${ }^{29}$ (dependendo, assim, das caracterís-

area within as well as exceeding $200 \mathrm{~nm}$ ".

25 Os Casos da Plataforma Continental do Mar do Norte foram os primeiros casos de delimitação de uma plataforma continental a ser decididos por um tribunal e, assim, a decisão proferida nos mesmos foi o grande ponto de partida para o estudo c consagração das regras relativas à delimitação dos espaços marítimos entre Estados. Efectivamente, na decisão destes casos resultaram algumas regras importantes que desde essa altura têm influenciado a prática da delimitação dos espaços marítimos. Neste sentido, vide MARQUES ANTUNES, A Delimitặ̃̃o de Espaços..., cit., pág. 94.

26. No âmbilo deste estudo, milha refere-se à milha marítima, a que correspondem 1852 metros. Sempre que daqui em diante se fizer referência às 200 milhas marítimas ter-se-á em consideração que essa distância é medida tendo en conta as linhas de base a partir das quais se mede a largura do mar territorial. Sobre a importância das linhas de base na fixação e delimitação dos espaços marítimos, vide PHARAND, "The Law of the Sea...", cil., pág. 9 a 11.

27 Neste sentido, vide Jean-Maurice ARBOUR, "Les Limites du Plateau Continental et de la Zone Economique Exclusive - Les fondements du titre de l'État sur les espaces maritimes et ses rapports avec l'opération de délimitation", in PHARAND, Donat / LEANZA, Umberto (edits), The Continental Shelf and the Exclusive Economic: Zone - Delimitation and Legal Regime / Le platean continental el la zone économique exclusive, Martinus Nijhoff Publishers, Dordrecht - Boston -- London, 1993, pag. 15.

28 Cujo objecłivo foi não prejudicar os Estados com plataformas continentais muito diminutas ou mesmo inexistentes, como, por exemplo, o Chile, o Peru e a Noruega. Neste sentido, vide ARBOUR, "Les Limiles du Plateau Continental...", cit, pág. 14 ; e Albino de AZEVEDO SOARES, Lições de Direito internacional Público, 4" Edição (Reimpressão), Coimbra Edilora, Coimbra, 1996, pág. 252.

29 Todavia, mesmo aqui existem limites máximos estabelecidos através de critérios de distância previstos nos n's 5 e 6 do artigo $76^{\circ}$. No que concerne à extensão da plataforma continental atém das 200 milhas, LILJE-JENSEN e THAMSBORG, "The role of Natural Prolongation...", cit., pág. 630, afirmam que existem duas correntes de pensamento: uma que entende que o espaço para lá das 200 milhas "form an integral part of the (legal) continental shelf" enquanto que outros consideram que "constitute a sort of surplus of shelf, something extra, calling for special legal treatment, in particular in relation to delimitation", embora, mais à frente, na pág. 640 do mesmo artigo, afirmem 
ticas concretas da mesma ${ }^{30}{ }^{31}$ ), mas dependente de uma declaração do Estado, pois, neste caso, os limites terão de ser submetidos à Comissão de Limites para efeitos de homologação ${ }^{32}$.

Convém, todavia, referir que a redacção do artigo $76^{\circ}$ é bastante complexa, dado que se combinam vários critérios alternativos ${ }^{33}$ (que, no entanto, são condicionados por limites máximos quanto à extensão da plataforma), sendo utilizados conceitos pertencentes a outras áreas do saber, cuja concretização prática é, por vezes, bastante difícil ${ }^{34}$, enquanto que para a correcta interpretação de certas partes é imprescindível a intervenção de um jurista, como por exemplo a parte da alínea b) do $n^{\circ} 4$ em que se refere "Salvo prova em contrário".

A plataforma continental tem uma dimensão muito incerta, oscilando em média entre 67 a $75 \mathrm{~km}$. Com efeito, tanto há locais em que a mesma nem sequer existe, como acontece, por exemplo, na Riviera Francesa, ao in-

que as regras do artigo $83^{\circ}$ se aplicam a toda a plataforma continental.

30) O que conduzirá a que a extensão da plataforma continental a que cada Estado terá direito dependa do que a «mãe natureza» the tiver concedido. Neste sentido, afirma LOUREIRO BASTOS, A Intemacionalização dos Recursos Naturais..., cit., pág. 283, que "não cabe ao regime juridico da plataforma continental proceder à correç̧ão das desigualdades da distribuição natural".

31 Neste caso mantém-se, portanto, o princípio do prolongamento natural do território dos Estados, consagrado em virtude de pressões exercidas pelos Estados com plataformas continentais muito extensas. Neste sentido, vide ARBOUR, "Les Limites du Plateau Continental...", cit., pág. 18.

${ }^{32}$ MARQUES ANTUNES, Towards the Conceplualisation..., cit., pág. 333, refere-se a "technical homologation"; e McDORMAN, "The Role of the Commission on the Limits of the Continental Shelf: A Teehnical Body in a Political World", in The International Jownal of Marine and Coasfal Law, Volume 17, 2002, pág. 301, considera a Comissão como "a legitimator of the claims". Preferimos a palavra homologação em detrimento de «controlo» por considerarmos a primeira mais adequada tendo em conta os escassos poderes de que a Comissão de limites dispôe.

${ }^{33}$ Critérios alternativos que tanto existem no que concerne ao estabelecimento do bordo exterior da margem continental, em que tanto se pode usar a fómula Gardiner - prevista no artigo $76^{\circ}, n^{\circ} 4$, alínea a), i) - como a fórmula Hedberg - consagrada no artigo $76^{\circ}, n^{\circ}$ 4 , alínea a), ii) -, como no que diz respeito aos limites máximos desse bordo, previstos no artigo $76^{\circ}, 11^{\circ} 5$ - 350 milhas das linhas de base a partir das quais se mede a largura do mar territorial ou a uma distância máxima de 100 milhas da isóbata dos 2500 metros.

${ }^{34}$ Nomeadamente, a fixação da isóbata de 2500 metros, a determinação com rigor do sítio em que se situa o pé do talude continental e a determinação da variação máxima do gradiente. 
vés de outros em que atinge $500 \mathrm{Km}^{35}$, como na Argentina e na Austrália.

A importância da plataforma continental, que determina o interesse dos Estados em relação a ela, advém dos recursos existentes na mesma. A este respeito o $\mathrm{n}^{\circ} 4 \mathrm{do}$ artigo $77^{\circ}$ refere que "Os recursos naturais a que se referem as disposições da presente parte são os recursos minerais e outros recursos não vivos do leito do mar e subsolo, bem como os organismos vivos pertencentes a espécies sedentárias, isto é, aquelas que no período de captura estão imóveis no leito do mar ou no seu subsolo ou só podem mover-se em constante contacto físico com esse leito ou subsolo".

Efectivamente, trata-se de um espaço bastante rico, nomeadamente em petróleo ${ }^{36}$, mas é igualmente uma importante fonte de gás natural, areia, pláceres de ouro, estanho, titânio, carvão de pedra, cobre, ferro, níquel, crómio, entre outros ${ }^{37}$.

No que diz respeito aos recursos vivos ${ }^{38}$ existentes na plataforma devemos referir o peixe, desde que pertencente a espécies sedentárias ${ }^{39}$ (de acordo com o disposto no $n^{\circ} 4$ do artigo $77^{\circ}$ ). Com efeito, as reservas piscícolas assumem uma importância fundamental, uma vez que a fauna marítima é bastante mais abundante em zonas próximas de terra do que em águas pro-

${ }_{35}$ Cfr: Jónatas E. M. MACHADO, Direito Internacional, Do Paradigma Clássico Ao Pós-1/ de Setembro, 2 Edição, Coimbra Editora, Coimbra, 2004, pág. 173 ; e PULVENIS, "The Continental Shelf Definition...", cit., pág. 319.

3 Desde os finais da década de sessenta do século XX que existiam estudos que demonstravam que as jazidas de petróleo susceptiveis de exploração comercial se situavam na margem continental. Sobre o desenvolvimento da tecnologia de exploração dos recursos minerais, em especial do petróleo, a seguir à $2^{a}$ guerra mundial, vide MOUTON, "The Continental Shelf", cit, pág. 353 e 354.

${ }^{37}$ Neste sentido, vide PULVENIS, "The Continental Shelf Definition...", cit, pág. 321.

${ }^{38}$ No que diz respeito à dificuldade em definir o que se entende por "organismos vivos", vide PULVENIS, "The Continental Shelf Definition...", cit, pág. 365, que acrescenta que há toda a vantagem em efectuar essa definição e, assim, determinar sc os mesmos se incluem na plataforma continental ou na zona económica exclusiva, uma vez que, se se incluírem nesta última, o Estado estará obrigado a autorizar os outros Estados a explorar a parte que o próprio não possa levar a cabo (cfr. artigo $62^{\circ}, n^{\circ} 2$ ), enquanto que no caso da plataforma continental isso não acontece.

39) No que concerne às espécies sedentárias e à polénica em relação ao que as mesınas abrangem, vide, inter atia, CHURCHILL e LOWE, The Law of the Sea, cit, pág. 130. Ian BROWNLIE, Principles of Public Imernationat Law, Fifth Edition, Ox ford University Press, Oxford, 1998, pág. 216, entende que ficam excluídas á solha e a albacora. 
fundas. Assumem, ainda, um enorme relevo económico, em certos sítios do globo, a pesca das pérolas, das ostras e a exploração de esponjas e de algas ${ }^{40}$.

\section{PODERES DO ESTADO COSTEIRO}

Tal como dispõe o $\mathrm{n}^{\circ} 1$ do artigo $77^{\circ}$ da Convenção de Montego Bay, o Estado costeiro dispõe em relação à plataforma continental de direitos de soberania -- «sovereign rights» - no que diz respeito à exploração e aproveitamento ${ }^{41}$ dos seus recursos naturais. Também a Convenção de Genebra, no seu artigo $2^{\circ} n^{\circ}$ l, consagrava esta regra. Já no decorrer da elaboração da Convenção de Genebra, a questão dos poderes do Estado costeiro tinha sido controversa devido à intenção manifestada pelos Estados de que os seus direitos sobre a plataforma fossem exclusivos, de que não os perdessem caso não procedessem à efectiva exploração daquela zona e de que a navegação no espaço em causa continuasse a ser livre ${ }^{42}$.

Contudo, o problema foi ultrapassado através da adopção da expressão «sovereign rights» que, assim, constitui uma solução de compromisso, em detrimento da referência a «controlo e jurisdição» prevista na proposta da Comissão de Direito Internacional. Desta forma, de acordo com o disposto no $\mathrm{n}^{\circ} 2$ do artigo $77^{\circ}$, "se o Estado costeiro não explora a plataforma continental ou não aproveita os recursos naturais da mesma, ninguém pode empreender estas actividades sem o expresso consentimento desse Estado". Ou seja, o Estado goza de direitos exclusivos que não tem de partilhar com outros Estados ${ }^{43}$, a não ser no caso específico do artigo $82^{\circ}$ da Convenção de Montego Bay. Efectivamente, de acordo com este último artigo, nos casos em que o Estado tenha direitos sobre uma plataforma continental além das 200 milhas maritimas,

\footnotetext{
"4) Cfr. MOUTON, "The Continental Shelf", cit, pág. 351; e PULVENIS, "The Continental Shelf Definition...", cit., pág. 324.

${ }^{41}$ As condiçóes em que a exploração e o aproveitamento irão ocorrer serão determinados pelo Estado costeiro na sua legislação interna. Neste sentido, vide CHURCHILL e LOWE, The law of the Sea, cit., pág. 128.

${ }^{42}$ Cfr. LOUREIRO BASTOS, A Internacionalizaçăo dos Recursos Naturais..., eit., pág. 291.

43. Regra essa que o Tribunal Internacional de Justiça já havia afirmado aquando dos Casos da Plataforma Continental do Mar do Norte, International Court of Justice Reports 1969, pág. 22, par. 19
} 
terá de efectuar pagamentos ou contribuições em espécie relativos ao aproveitamento que faça dos recursos não vivos além das 200 milhas, que serão distribuídos pela Autoridade Internacional dos Fundos Marinhos $^{44}$ aos Estados Partes na Convenção ${ }^{45}$.

Além disso, o Estado detém poderes de soberania sobre os espaços em questão ainda que não os ocupe ou explore efectivamente ${ }^{46}$, sendo os mesmos independentes de qualquer declaração expressa (quer se baseiem num critério de distância - até às 200 milhas - ou no prolongamento natural - além das 200 milhas $^{47}$ ). Neste sentido, o n 3 do artigo $77^{\circ}$ refere que "Os direitos do Estado costeiro sobre a plataforma continental são independentes da sua ocupação, real ou fictícia, ou de qualquer declaração expressa"48. Com efeito, trata-se de direitos inerentes, uma vez que existem ipso facto e ab initio, não estando dependentes de nenhuma revindicação por parte do Estado ${ }^{49}$. Já nos Casos da

${ }^{4}$ Apelidada abreviadamente por «Autoridade» (nomeadamente na Convenção de Montego Bay - cfr. artigo $1^{\circ}, \mathrm{n}^{\circ} \mathrm{l}$, alínea 2)) e daqui em diante assim designada neste estudo.

4.5 De acordo com PULVENIS, "The Continental Shelf Definition...", cit., pág. 362, trata-se da maior inovação da Convenção. Segundo Kemal BASLAR, The Concept of the Common Heritage of Mankind in International Law, Martinus Nijhoff Publishers, The Hague - Boston - London, 1998, pág. 239, "This article as a whole is an incipient form of the common heritage of mankind". De acordo com Tim HILLIER, Principles of Public Intenational Law, $2^{a}$ Edição, Cavendish Publishing Limited, London - Sydney, 1999, pág. 201, este foi un aspecto bastante controverso da Convenção.

460 Estado pode inclusivamente conceder a exploração a investidores estrangeiros, o que aliás, os páses menos desenvolvidos fazem frequentemente. Cir. Shigeru ODA, "Internalional Law of the resources of the sea", in RDC, volume 127, 1969 -- II, pág. 442.

${ }^{47}$ Neste sentido, vide MARQUES ANTUNES, Towards the Conceptualisation..., cit., pág. 333; c MARQUES ANTUNES e PIMENTEL, "A Extensão da Plataforma Continental...", cit., pág. 324.

${ }^{48}$ Regra essa que já se encontrava prevista na Convenção de Gencbra, mais concretamente no seu artigo $2^{\circ}, n^{\prime \prime} 3$.

${ }^{49}$ Neste sentido, vide Casos da Plataforma Continental do Mar do Notte International Court of Justice Reports 1969, pág. 22, par. 19; PULVENIS, "The Continental Shell Definition...", cit., pág. 370; LUCCHINI e VOELCKEL, Droit de la Mer..., cit., pág. 258, que além disso afirmam tratar-se de "d'un droit inaliénable ef inprescriptible"; $\mathrm{e}$ VALLE, "A Plataforma Continental...", cil., pág. 46, que afirma que "a sua existência pode ser reconhecida e declarada, mas sem qualquer efeito constitutivo", embora não concordemos com o autor quando o mesmo se refere ao "carácter não inerente dos direitos" no que concerne ao espaço além das 200 milhas e que os mesmos "dependem de declaração expressa", pois consideramos que o artigo $77^{\circ}$ se aplica a toda a plataforma, 
Plataforma Continental do Mar do Norte o Tribunal Internacional de Justiça havia afirmado "the coastal state as having an original, natural, and exchusive (in short a vested) right"

Por outro lado, tendo em conta o disposto no artigo $78^{051}$ da mesma. Convenção, a liberdade de navegação nas águas suprajacentes (pertencentes à zona económica exclusiva ou ao alto mar) mantém-se ${ }^{52}$. Com efeito, os direitos do Estado costeiro não são ilimitados ${ }^{53}$.

\section{A COMISSÃO DE LIMITES DA PLATAFORMA CONTINENTAL}

Tal como vimos supra, sempre que um Estado pretenda e para isso reúna as condições necessárias para proceder ao alargamento da sua plataforma continental além das 200 milhas terá de efectuar uma submissão nesse sentido à Comissão de Limites $^{54}$ da Plataforma Con-

até c além das 200 milhas.

5o Casos da Plataforma Continental do Mar do Norte, International Court of Justice Reports 1969, pág. 32 e 33, par. 47.

${ }^{51}$ De acordo com A. A. KOVALEV, Contemporary Issues of the Law of the Sea: Modern Rusisian Approaches, Eleven International Publishing, Utrecht, 2004 (Tradução inglesa efectuada por W. E. Butler), pág. 95, este artigo "guarantees nore fully the rights and freedoms of all States, is more precise, and encompasses a broader group of questions in comparison with the 1958 Convention".

${ }^{52}$ Regra essa que o Tribunal Internacional de Justiça já tinha considerado como norma costumeira nos Casos da Plataforma Continental do Mar do Norte, International Court of Justice Reports 1969 , pag. 39 , par. 63.

53 Neste sentido, vide CHURCHILL e LOWE, The Law of the Sea, cit., pág. 129.

${ }^{54}$ Para mais informações sobre a Comissão de Limites, vide o seu site em http://www. un.org/Depts/los/cles new/cles home.htm (consultado em 18/03/2006). Sobre as negociações no seio da III Conferência que conduziram à criação da Comissão de Limites, vide Annick de MARFFY-MANTUANO, "La fixation des dernières limites maritimes: Le rôle de la Commission des Limites du plateau continental", in LUCCHINI, Laurent / QUÉNEUDEC, Jean-Pierre (edits), La Mer et son Droit, Pedone, Paris, 2003, pág. 400 a 403 . Sobre as polémicas que envolveram a Comissão de Limites no decorrer das negociações da Convenção, vide BROWN, Sea-Bed Ennergy..., cit., pág. 28 a 32 . De acordo com McDORMAN, "The Role of the Commission...", cit., pág. 301, a referida Comissão "was established as part of the careful compromises respecting Article 76 and the formula therein for the determination of the outer limits of the continental shelf". Sobre a questào de saber se a Comissão representa alguém e, em caso afirmativo, quem, vide McDORMAN, "The Role of the Commission...", cit., pág. 311 a 313. 
tinental, não se tratando assim de uma fixação unilateral por parte daquele ${ }^{55}$.

Desta forma, a Comissão de Limites foi criada com o objectivo de supervisionar a extensão das plataformas continentais além das 200 milhas, garantindo que os artigos da Convenção de Montego Bay relativos a esse assunto sejam correctamente aplicados e tentando evitar que sejam estabelecidas plataformas continentais exageradas ${ }^{56}$.

De acordo com o disposto no artigo $2^{0}$, do Anexo $\mathrm{II}^{57}$, da Convenção, a Comissão é composta por 21 membros, "peritos em geologia, geofisica ou hidrografia" 58 (...) "tendo na devida conta a necessidade de assegurar uma representação geográfica". É compreensível que a mesma seja constituída por peritos ${ }^{59}$ nessas áreas, uma vez que a sua tarefa irá recair sobre a análise de questões eminentemente técnicas relativas aos limites da margem continental (principalmente os seus aspectos físicos) e sobre o complexo artigo $76^{\circ}$. Todavia, manifestamos aqui a nossa perplexidade e preocupação pelo facto de não se encontrar prevista a presença de um jurista ${ }^{60}$. Com efeito, tal como já tivemos oportunidade de referir supra, e analisaremos também infra, muitas das questões relativas à plataforma continental além das 200 milhas exigem conhecimentos jurídicos que os referidos peritos poderão não, nem lhes será exigível, possuir e compreender. Embora os referidos membros sejam eleitos pelos Estados Partes na

55 É exactamente por este motivo que consideramos estar aqui em presença de uma delimitação e não de uma fixação da plataforma continental. Neste sentido, vide LOUREIRO BASTOS, A Internacionalização dos Recursos Naturais..., cit., pág. 317.

${ }_{56}^{5}$ Nesse sentido, PULVENIS, "The Continental Shelf Definition...", cit., pág. 357, considera a Comissão de Limites um "supervisory body". Sobre a tarefa desempenhada pela Comissão de Limites, vide McDORMAN, "The Role of the Commission...", cit., pág. 319 a 321.

57 Todos os artigos referidos neste ponto sem indicação de proveniência serão relativos ao Anexo II da Convenção de Montego Bay.

58 Assim se assegurando a sua competência, independência e imparcialidade na opinião de PULVENIS, "The Continental Shelf Definition...", cit., pág. 358.

${ }^{59}$ De salientar que actualmente um dos membros da Comissão tem a nacionalidade portuguesa.

${ }^{60}$ Nesse sentido, vide Nuno MARQUES ANTUNES e Fernando M. PIMENTEL, "Reflecting on the Legal-Technical Interface of Article 76 of the Losc: Tentative Thoughts on Practical Implementation", in MARQUES ANTUNES, Nuno (edit), Estudos em Direito Internacional Público, Almedina, Coimbra, 2004, pág. 345 e 346; e BROWN, Sea-Bed Energy..., cit., pág. 31. 
Convenção de Montego Bay, devem exercer as suas competências de uma forma imparcial. No entanto, consideramos que este objectivo talvez possa vir a ser posto em causa pelo facto de ser o Estado que patrocinou a candidatura que suporta as despesas daquele ${ }^{61}{ }^{62}$ (cfr. artigo $2^{\circ}, n^{\circ} 5$ ). Contudo, devemos salientar que, numa tentativa de assegurar uma certa transparência a todo o processo, se estabelece no artigo $5^{\circ}$ que um perito não poderá fazer parte da subcomissão que analisará a submissão do Estado da sua nacionalidade.

A Comissão de Limites desempenha uma importante funcão de homologação, prevista no artigo $3^{\circ}, n^{\circ} 1$, alínea a), do Anexo II, da Convenção. Com esse propósito, os Estados deverão apresentar-lhe submissões em que serão indicados os limites das suas plataformas, tendo em conta os critérios previstos no artigo $76^{\circ}$ da Convenção. A referida submissão será analisada por uma subcomissão criada para o efeito, tendo em conta os Scientific and Technical Guidelines da Comissão de Limites ${ }^{63}$. Caso a subcomissão não concorde com as indicações apresentadas pelo Estado costeiro, efectuará as recomendações ${ }^{64}$ que considere pertinentes, que serão adoptadas pela Comissão (cfir. artigo $6^{\circ}$ ). Todavia, os Estados não estão obrigados a aceitar as referidas reco-

"Neste sentido, vide Noel Newton St. Claver FRANCIS, "The Continental Shelf Commission", in NORDQUIST, Myron H. / MOORE, John Norton (edits), Oceans Policy

New Institutions, Challenges and Opportunities, Martinus Nijhoff Publishers, The Hague - Boston … London, 1999, pág. 144; e McDORMAN, "The Role of the Commission...", cit., pág. 312, que, na pág. 311, chama a atençấo para o facto de a Autoridade não se encontrar representada na Comissão.

62. Contudo, convém salientar que foi criado um fundo destinado a suportar as despesas dos membros da Comissão que sejam nacionais de paises em desenvolvimento para que possam participar nos trabalhos da Comissão [Voluntary fund to enable the participation of the members of the Commission from developing countries in the work of the Commission by meeting their costs of participation (travel expenses and daily subsistence allowance), cujo texto está disponivel no site da Comissão de Limites, mais concretamente em http://www.un.org/Depts/los/cles_new/voluntary_fund membersCLCS.htm, consultado em 19/03/2006 (mas contendo a indicaçăo de que não se trata de um documento oficial)].

63 Scientific and Technical Guidelines of the Commission on the Limits of the Continental Shelf, UN Doc. CLCS/11, 13 May 1999.

${ }^{64}$ No entanto, as recomendações não poderão colocar $\mathrm{cm}$ causa a delimitação da plataforma continental entre Estados com costas adjacentes ou opostas (prevista no artigo $83^{\circ}$ ), mas prevalcee sobre a delimitação das plataformas em relação à Área, como veremos infra (cfi artigo $9^{\circ}$, do Anexo lI, artigo $76^{\circ}, n^{\circ} 10$ e $134^{\circ} n^{\circ} 4$ ). 
mendações. Com efeito, apenas não as podem ignorar, sendo-thes dada a possibilidade de efectuar uma proposta revista ou uma nova proposta, de acordo com o disposto no artigo $8^{\circ}$.

De acordo com o disposto no $n^{\circ} 8$ do artigo $76^{\circ}$ da Convenção, se o Estado atender às recomendações efectuadas pela Comissão, os limites que daí resultarem serão definitivos e obrigatórios ${ }^{65}$.

A apresentação das submissões dos Estados deverá ter lugar, de acordo com o artigo $4^{\circ}$, no prazo de 10 anos a contar da data em que a Convenção de Montego Bay entrou em vigor em relação a cada Estado individualmente. Contudo, os Estados Partes da mesma acordaram ${ }^{66} 67$ que o referido prazo fosse contado apenas a partir de 13 de Maio de 1999, altura da publicação dos Scientific and Technical Guidelines da Comissão de Limites, dado que apenas após essa data os Estados tiveram conhecimento dos documentos básicos necessários às submissões e de informações relativas à complexa preparação das mesmas. Desta forma, o prazo termina em 13 de Maio de 2009, para todos os Estados em relação aos quais a Convenção entrou em vigor antes de 13 de Maio de 1999, enquanto que para os Estados em relação aos quais a Convenção apenas entrou em vigor após 13 de Maio de 1999, o prazo de 10 anos conta-se normalmente a partir dessa data ${ }^{68}$. No que concerne aos

65. Conludo, cmbora seja com base nas recomendações efectuadas pela Comissão, na verdade quem estabelece os limites exteriores da plataforma continental é o Estado e não ela. Sobre o carácter definitivo e obrigatório do limite assim estabelecido, nomeadamente quanto a outros Estados, vide McDORMAN, "The Role of the Commission...", cit., pág. 314 e 315 , que, nas págs. 313 a 317 , analisa o significado do artigo $76^{\circ}, n^{\circ} 8$.

oo Decision regarding the date of commencement of the ten-year period for making submissions to the Commission on the Limits of the Continental Shelf set out in article 4 of Annex II to the United Nations Convention on the Law of the Sea, Meeting of the State Parties, Eleventh Meeting, New York, 14-18 May 2001 (SPLOS/72).

(1) Principalmente devido às preocupações manifestadas pelos paises en desenvolvimento que entendiam não conseguir cumprir o prazo se este fosse contado tendo em conta o attigo $4^{\circ}$. Tal como é afirmado no documento lssues with respect to article 4 of Annex // to the Convention, disponivel no site da Comissão de Limites, mais concretamente em http:/www.um.org/Depts/os/eles new/issues ten_years.htm, consultado em $5 / 02 / 2006$ (mas contendo a indicação de que não se trata de um documento oficial).

6 No entanto, talvez este prazo deva ser suspenso caso o Estado se encontre em processo de delimitação com outro, una vez que, tal como vimos infra, essa delimitação prevalece. Contudo, essa possibilidade de suspensão não se encontra expressamente prevista. Nesse sentido, vide LOUREIRO BASTOS, A Internacionalização dos Recur- 
Estados não partes na Convenção entendemos não thes ser aplicável o prazo de 10 anos, nem a necessidade de efectuar uma submissão à Comissão de Limites.

Apesar da indiscutível importância das tarefas a cargo da Comissão de Limites, muitas são as questões relativas à mesma e envolvendo o seu intrincado trabalho que foram deixadas sem resposta, e para a resolução das quais entendemos ser necessária a intervenção de um jurista, tais como: a falta de previsão do procedimento a seguir caso a Comissão volte a discordar da proposta revista ou nova apresentada pelo Estado na sequência das recomendações daquela ${ }^{(\%)}$; não se esclarece em que consiste o prazo razoável a que o artigo $8^{\circ}$ faz referência ${ }^{70}$; qual o comportamento a adoptar caso um Estado não parte na Convenção de Montego Bay apresente uma submissão à Comissão ${ }^{71}$; o facto de não ser

sos Naturais..., cit., pág. 342.

(1) Com efeiro, nem o $n^{\circ} 8$ do artigo $76^{\circ}$ da Convenção, nem o artigo $8^{\circ}$ do Anexo Il, nem ainda o $1^{\circ} 4$ da regra 53 das Regras de Processo da Comissão de Limites (Rules of Procedure of the Commission on the Limits of the Continental Shelf, UN Doc. CLCS/40, 2 July 2004) resolvem a questão. Assim sendo, em teoria parece que o processo se pode desenrolar ad etermum, até o Estado aceitar as recomendações da Comissão de Limites. Neste sentido, vide PULVENIS, "The Continental Shelf Definition...", cit, pág. 362; Robert SMITH, "The Continental Shelf Commission", in NORDQUIST, Myron H. MOORE, John Norton (edits), Oceans Policy New lnstituions, Challenges and Opportunities, Martinus Nijhoff Publishers, The Hague - Boston - London, 1999, pág. 139; e MARFFY-MANTUANO, "La fixation...", cit., pág. 416. Além disso, não é claro se esta matéria está ou não incluída na jurisclição obrigatória prevista na Parte $X V$ da Convenção de Montego Bay. Neste sentido, vide McDORMAN, "The Role of the Commission...", cil., pág. 317 e 318 , que entende que esta questão se deve à falta de consenso no que a este assunto diz respeilo durante as negociações da Convenção. Sobre a relação entre o artigo $76^{\circ}$, a Comissäo de Limiles e a Parte XV da Convenção, vide McDORMAN, "The Role of the Commission..., cit., pág. 317 a 319. De acordo com The Law of The Secr Definition..., cil., pág. 29, a Parte XV, Secção 2, da Convenção não estabelece uma jurisdição obrigatória no que concerne às dispulas relativas ao artigo $76^{\circ}$.

70 Neste sentido, vide PULVENIS, "The Continental Shelf Definition...", cit., pág. 362.

${ }^{7}$ Quanto a este assunto, somos da opinião que a Comissão de Limiles não deverá analisar a reforida submissão dado que a criação da mesma resulta da Convenção de Montego Bay, assim como o alargamento da plataforma continental de acordo com os critérios previstos no artigo $76^{\circ}$ da mesma, o que implica a prévia aceitação da Convenção (obviamente na sua totalidade, e não apenas numa parte da mesma) pelos Estados - através de ratificação ou adesão, tal como disposto nos artigos $306^{\circ}$ e $307^{\circ}$ (aceitação) essa que, conforme resulta a contrario do artigo $309^{\circ}$, nem sequer admite a aposição de reservas no que diz respeito à delimilação da plataforma continental). Contudo, 
prevista qualquer sanção caso os Estados não cumpram o prazo dos 10 $\operatorname{anos}^{72}$; e se se vier a entender que nesse caso há lugar a responsabilidade internacional, surge o problema de determinar qual o sujeito de Direito Internacional cujo direito foi violado ${ }^{73}$. Estas últimas questões assumem um enorme relevo porquanto até à presente data ${ }^{74}$ apenas oito Estados apresentaram as suas submissões (a Rússia ${ }^{75}$ o Brasil, a Austrália, a Irlanda, a Nova Zelândia, a França, a Espanha e o Reino Unido $)^{76}$. Em Portugal, sendo este um dos países com condições para

segundo MARFFY-MANTUANO, "La fixation...", cit., pág. 408, no futuro a Comissão de Limites poderá analisar as submissões tendentes ao alargamento que Estados não partes na Convenção the venham a apresentar. De acordo com McDORMAN, "The Role of the Commission...", cit., pág. 304, já actualmente um Estado năo parte pode efectuar uma submissão à Comissão. A Comissão, certamente prcocupada com esta eventualidade, solicitou uma opiniăo sobre este assunto. Na Oitava Reunião dos Estados Partes em 1998, entendeu-se que a questão não necessitava de ser respondida até a situação se concretizar. Cfr. Report of the Eighth Meeting of the State Parties, doc. SPLOS/31, parágrafo 52 .

72 Todavia, entendemos que os espaços não «reivindicados» pelos Estados até essá data não passam a constituir território da Área, com a consequente perda pelos Estados do seu direito à plataforma continental, tendo em conta a natureza dos direitos dacueles, que, de acordo com o artigo $77^{\circ}$, são "exchusivos" e "independentes de qualquer declaração expressa". Nesse sentido, vide LOUREIRO BASTOS, A Iniernacionalização dos Recursos Naturais..., cil., pág. 341; e MARFFY-MANTUANO, "La fixation...", cit., pág. 407. Em sentido contrário, entendendo que esse espaço passará a integrar a Área, não podendo depois disso vir a ser reclamado pelo Estado costeiro, vide SOARES, "Plataforma Continental...", cit., pág. 39 e 40; e José Luís MOREIRA DA SILVA, Direito Internacional e Direilo do Mar (Sumários Desenvolvidos Parte II) - Direito do Mar, Associação Académica da Faculdade de Direito de Lisboa, Lisboa, 2003, pág. 84. VALLE, "A Plataforma Continental...", cit., pág. 47, entende que os 10 anos se trata de um prazo de prescrição.

73 Nesse sentido, vide LOUREIRO BASTOS, A Internacionalização dos Recursos Nahurais..., cit., pág. 343.

74 Referimo-nos à dala de $06 / 10 / 2006$.

75 O sumário das recomendações efectuadas consta do Relatório do Secretário Geral apresentado à $57^{\prime}$ Sessão da Assembleia Geral da ONU, no item da agenda relativo aos Oceanos e ao Direito do Mar (A/57/57/Add.1, of 8 October 2002, par. 38-41).

76. Mais informações sobre as submissões apresentadas pelos Estados, incluindo os sumários das mesmas, mapas ilustrativos dos limites exteriores da plataforma continental por si propostos, assim como as declarações apresentadas pelos restantes Estados ern resposta às submissôes, entre outras informações, podem ser obtidas no site da Comissão de Limites, em http://www.un.org/Depts/los/ctes_new/cles_home.htm (consultado em 11/10/2006). 
proceder ao alargamento da plataforma continental além das $200 \mathrm{mi}$ Ihas ${ }^{77}$, foi criada para o efeito a Estrutura de Missão para a Extensão da Plataforma Continental que se encontra a preparar a submissão que será apresentada à Comissão de Limites ${ }^{78}$.

A Comissão desempenha igualmente uma função de assessoria. Com efeito, de acordo com a alínea b) do $\mathrm{n}^{\circ} 1$ do artigo $3^{\circ}$, a Comissão também poderá ajudar os Estados, a pedido destes, na preparação dos dados necessários à apresentação das informações relativas aos limites exteriores da plataforma continental, que são bastante técnicos, complexos, e para a obtenção dos quais são necessárias avultadas somas de dinheiro ${ }^{79}$. Contudo, com o objectivo de garantir a imparcialidade no funcionamento da Comissão previu-se que os membros da Comissão que tenham prestado assessoria científica e técnica ao Estado costeiro não farão parte da subcomissão que irá proceder à análise da submissão apresentada por este (cfr. artigo $\left.5^{\circ}\right)^{80}$. Como se comprende trata-se de

${ }^{77}$ De acordo com The Law of The Sea-Definition ..., cit., pág. 6 e 32, nota de rodapé 21 foram identificados cerca de 30 países (embora se acrescente que esta lista não deve ser considerada definitiva) com possibilidade de estenderem a sua plataforma além das 200 milhas: África do Sul, Angola, Argentina, Austrália, Brasil, Canadá, Dinamarca, Equador, Espanha, EUA, Fiji, França, Guiné, Guiana, Islândia, Índia, Indonésia, Irlanda, Japão, Madagáscar, Maurícia, México, Micronésia, Mianmar, Namíbia, Nova Zelândia, Noruega, Portugal, Reino Unido, Rússia, Seicheles, Suriname e Uruguai.

7. Mais informações sobre a referida Estrutura poderão ser encontradas no seu site em http://www.emepc.gov.pt/entrada.htm (consultado em 06/10/2006).

72 Neste sentido foi criado um fundo destinado a auxiliar os Estados em desenvolvimento (principalmente os Estados menos desenvolvidos e os Estados em desenvolvimento formados por pequenas ilhas) na elaboração dos estudos necessários à apresentação das Submissões à Comissão de Limites da Plataforma Continental, sempre que a plataforma se estenda além das 200 milhas: Trust fund for the purpose of facilitating the preparation of submissions to the Commission on the Limits of the Continental Shelf for developing States, in particular the least developed countries and small istand developing States, and compliance with article 76 of the United Nations Convention on the Law of the Sea, cujo texto se encontra disponível no site da Comissão de Limites, mais concrelamente em http://www.un.org/Depts/los/cles_new/trust_fund_article76. him, consultado em 19/03/2006 (mas contendo a indicação de que não se trata de um documento oficial).

81) No entanto, não se esclarece se se trata de assessoria científica e lécnica prestada pela Comissão ao abrigo do disposto no artigo $3^{\circ}, n^{\circ} 1$, alínea b), do Ancxo ll ou se se trata de acessoria concedida pelos seus membros a título individual. De acordo com o primeiro sentido, vide Richard HAWORTH, "The Continental Shelf Commission", in NORDQUIS'T, Myron H. / MOORE, John Norton (edits), Oceans Policy-New Institu- 
uma competência muito delicada que apenas consiste numa ajuda à preparação dos dados necessários para efectuar a submissão e não na fixação concreta dos limites da plataforma ${ }^{81}$.

\section{A RELAC ÃO ENTRE A PLATAFORMA CONTINENTAL E A ÁREA}

De acordo com o disposto na alínea 1), do $n^{\circ} 1$, do artigo $1^{\circ}$, da Convenção de Montego Bay, a Área corresponde ao "leito do mar; os fundos-marinhos e o seu subsolo além dos limites da jurisdição nacional". Trata-se, portanto, da zona terrestre do fundo do mar situada para além dos limites da jurisdição dos Estados, que constitui um espaço internacionalizado. A Área é património comum da humanidade, assim como os recursos existentes na mesma (cfr. artigo $136^{\circ}$ ), e para a sua exploração foi criada a Autoridade Internacional dos Fundos Marinhos ${ }^{82}$. Consequentemente, nenhum Estado pode exercer direitos de soberania sobre espaços pertencentes à Área (cfr. artigo $137^{\circ}$ ), que, assim, constitui um limite à expansão daqueles.

Desta forma, entre a plataforma continental dos Estados e a Área existirá uma fronteira, separando dois espaços com regimes completamente distintos. Assim, entendem o que existirá aqui um problema de delimitação entre as plataformas e a Área, e não de fixação, uma vez que, pese embora o facto de não haver propriamente um consenso entre os Estados e a Autoridade no que diz respeito ao estabelecimento do referido limite, além de existir aqui uma fronteira, o limite exterior da plataforma não é fixado por acto unilateral dos Estados, porquanto estes estão sujeitos à homologação efectuada pela Comissão de Limites.

Contudo, e tal como já tivemos oportunidade de referir supra, a delimitação da Área será efectuada "a contrario", após o estabelecimento dos limites das plataformas continentais dos Estados, uma vez que a demarcação destas prevalece em relação à daquela (cfr. artigo $76^{\circ}, \mathrm{n}^{\circ}$ $10,134^{\circ} n^{\circ} 4$, e $9^{\circ}$, do Anexo II). Assim, as funções desempenhadas pela Comissão de Limites, embora estejam directamente vocacionadas para

fions, Challenges and Opportunities, Martinus Nijhofl Publishers, The Hague - Boston - London, 1999, pág. 152. De acordo com o último sentido, vide PULVENIS, "The Continental Shelf Definition...", cit., pág, 362.

st Cfr. PULVENIS, “The Continental Shelf Definition...", cit., pág. 361.

s. Cfr. AZEVEDO SOARES, Lições de Direito..., cit., pág. 255. 
a fixação dos limites exteriores das plataformas, acabam por, reflexamente, assumir um papel determinante na delimitação da Área. Podemos assim concluir que embora a criação da Área tenha constituído um grande passo no âmbito da Convenção de Montego Bay, os Estados não se preocuparam muito com a delimitação desta ${ }^{83}$.

Todavia, entendemos dever salientar que, ao contrário do que acontece com as plataformas continentais cuja demarcação é considerada mais premente, o mesmo não se passa, por agora, com a Área, uma vez que a delimitação desta não é uma operação tão necessária a curto prazo. Neste sentido, são avançados como argumentos o facto de a fixação dos limites daquele espaço internacionalizado, devido à sua extensão e profundidades, implicar custos avultados e o facto de não ser previsível a sua exploração económica intensiva nos tempos mais próximos ${ }^{84}$.

Muitos são os problemas que poderão vir a ocorrer relativamente à delimitação da Área.

Se se estiver perante uma plataforma continental de 200 milhas, os limites da Área coincidirão com os limites exteriores daquela, estabelecidos unilateralmente pelo Estado costeiro. Contudo, caso o Estado não tenha reivindicado a plataforma a que tem direito (o que ele não se encontra obrigado a fazer), ou se o tiver feito, mas não tenha fixado com precisão os limites desta, não poderá ser demarcada a Área. Uma das soluções apontadas para este problema poderia consistir na adopção do limite exterior da zona económica exclusiva, ou no estabelecimento de um limite provisório por parte da Autoridade ${ }^{85}$. Todavia, na nossa opinião, em ambos os casos existiria uma siluação de indefinição, com as desvantagens que lhe são inerentes.

Se se tratar de uma plataforma além das 200 milhas, consideramos que as dificuldades poderão ainda vir a ser maiores. Nesse caso, os limites da Área irão coincidir com os da plataforma desde que estes tenham sido homologados pela Comissão de Limites. Contudo, e tal como já vimos supra, uma vez que a demarcação da plataforma prevalece em relação à delimitação daquele espaço internacionalizado, esta não poderá ocorrer enquanto a Comissão de Limites não homologar os limi-

8. Nesse sentido, vide LOUREIRO BASTOS, A Imernacionalizaço dos Recursos Naturais..., cit., pág. 342.

${ }^{84}$ Neste sentido, vide idem, pág. 338.

85 Neste sentido, vide LOUREIRO BASTOS, A Internacionalização dos Recursos Naturais..., cit., pág. 340 . 
tes que the forem submetidos pelo Estado costeiro ${ }^{86}$.

Tanto no caso de existir uma plataforma de 200 milhas, como além das 200 milhas poderá ainda existir o problema de existirem pretensões opostas de vários Estados em relação ao mesmo espaço, sendo que também neste caso essa demarcação prevalece em relação à delimitação da Área ${ }^{87}$. Neste caso, uma solução possivel poderia consistir em suspender o prazo de 10 anos para apresentar a submissão à Comissão de Limites até a delimitação entre os Estados estar concluída ${ }^{38}$ (fazendo com que também a delimitação da Área ficasse suspensa) ou o referido prazo ser alargado. No entanto, esta suspensão ou o alargamento não se encontram previstos em nenhuma norma.

No que diz respeito à delimitação da Área na região da Antárctida trata-se de uma situação especial cuja resolução dependerá da forma como o regime jurídico dos dois espaços for compatibilizado entre $\mathrm{si}^{89}$.

A tudo isto acresce ainda o facto de entendermos que aos Estados não partes na Convenção de Montego Bay não thes é aplicável o prazo de 10 anos previsto, nem a necessidade de efectuar uma submissão à Comissão de Limites, o que contribui para tornar o problema da delimitação da Área ainda mais complexo.

Também no que a este assunto da delimitação da Área diz respeito entendemos ser deveras útil, e mesmo imprescindível, o contributo de um jurista, nomeadamente para a resolução de questões como a possibilidade de suspensão do prazo de 10 anos ou o seu alargamento.

86 Processo esse que, tal como vimos supra, se poderá desenrolar ad cternum, pelo menos em teoria, enquanto a Comissão não concordar com os limites apresentados pelo Estado.

87 Nesse sentido, no n" 3 do Anexo 1 das Regras de Processo da Comissão de Limites prevê-se expressamente a possibilidade de os Estados costeiros apresentarem apenas uma submissão parcial, ou seja, da parte que se encontra já delimitada cntre os Estados ou que não é objecto da delimitação entre estes, e no parágrafo $5^{\circ}$, alínea a), do Anexo I estabelece-se a impossibilidade de a Comissão analisar uma submissão relativa a espaços em que exista uma controvérsia entre os Estados, excepto se os próprios nisso concordarem.

s* Neste senlido, vide LOUREIRO BASTOS, A Internacionalização dos Recursos Naturais..., cit., pág. 339 e 342 .

8) Neste sentido, vide LOUREIRO BASTOS, A Internacionalização dos Recursos Naturais..., cit., pág. 340. 


\section{CONCLUSÕES}

As questões relacionadas com a plataforma continental, embora relativamente recentes no âmbito do Direito do Mar, constituem matérias com imenso relevo tanto do ponto de vista jurídico, como do ponto de vista económico, dada a riqueza dos recursos normalmente existentes nesse território.

Desta forma, a possibilidade, expressamente prevista na Convenção de Montego Bay, de os Estados costeiros alargarem os seus poderes de soberania além das 200 milhas constitui uma excelente oportunidade de estes ampliarem as suas zonas de exploração. Neste contexto, a Comissão de Limites, principalmente no que concerne à sua função de homologação, vai desempenhar um papel determinante c bastante delicado, inclusivamente em termos políticos.

Embora em todos estes assuntos se imbriquem conceitos pertencentes a várias áreas do saber, consideramos determinante o contributo prestado pelos juristas, numa matéria estritamente conexionada com os poderes jurídicos dos Estados em que existem alguns problemas ainda sem resposta. 